\section{Keep Australia's carbon pricing}

Australia's new government may ditch the nation's pioneering carbon-pricing scheme in a move that would send a negative signal to other countries with plans for carbon trading or taxation (see E. Diringer

Nature 501, 307-309; 2013). Researchers and policy-makers need to be more effective in communicating such schemes to the public, to help guard against adversarial politics leading to inferior policy outcomes.

In Australia's present carbonpricing system, emitters buy government permits for a fixed price of Aus $\$ 24$ (US\$22) per tonne of carbon dioxide produced. Under current law, this scheme is due to become a market-based emissionstrading scheme in 2015 and will allow trading with the cheaper emissions permits from the European Union.

The latest proposals retain Australia's target for lower emissions, but aim to replace the carbon-pricing scheme with government payments to companies that reduce emissions below a specified baseline. Critics include environmentalists, who fear that such a scheme would fail to meet Australia's emissions-reductions target, and economists, who say that it would compromise efficiency.

Although most experts regard a carbon price as the most efficient way of cutting emissions, it has been discredited in the popular discourse by opponents branding it as a punitive tax. In my view, inadequate communication with the public is partly to blame: Australia's former government failed to explain that carbon-pricing revenue is returned to low- and middle-income earners (under the new scheme, the taxpayer would pay to reduce emissions). Moreover, economists should have proclaimed their almost unanimous support for putting a price on carbon emissions.
Frank Jotzo Australian National University, Canberra, Australia. frank.jotzo@anu.edu.au

\section{Learn from China's local pilot schemes}

I agree that international road maps for reducing carbon emissions will ultimately depend on stitching together inspired local initiatives (E. Diringer Nature 501, 307-309; 2013). Good examples are the local pilot schemes set up nationwide in China (see, for example, Nature 498, 145-146; 2013).

The National Development and Reform Commission of China selected five provinces and eight cities in 2010 for the first round of low-carbon pilots, and has now included another province and 28 more cities in the second round. The scheme encourages policy innovation by local governments for low-carbon development and includes timetables for reducing greenhouse-gas emissions.

A survey by my team has revealed that several of these pilots are using innovative measures to upgrade conventional manufacturing and agriculture, to ensure that new industries, buildings and transportation conform with these plans, and to improve energy efficiency and carbon-sink capacity through ecological programmes.

Xufeng Zhu Tsinghua University, Beijing, China.

zhuxufeng@tsinghua.edu.cn

\section{Better drug access for terminal patients}

The distinguished statistician Les Halpin died last month from motor neuron disease, aged 56 . He was the founder of the Empower: Access to Medicine campaign to improve the availability of experimental therapies and to accelerate drug approval and licensing for people with life-threatening illnesses (see go.nature.com/v2nr3y).
After his diagnosis in May 2011, Halpin was surprised by the lack of treatments for people with his disease. This led him to ponder, from a statistical viewpoint, the regulatory systems that we apply to biomedical innovation, noting that they are much more riskaverse than the patients they are intended to serve. He believed that as a result, new medicines take longer to develop and are more costly than necessary.

His campaign has enabled drugs to get to market faster and more cheaply (see, for example, go.nature.com/gmgcyu). With support from academics, politicians and industrial scientists, he developed the Halpin Protocol (see go.nature. com/3z2wkd), which has sparked debate in the UK Parliament.

Halpin's campaign to overcome barriers to health-care translation will continue, aiming to lower them objectively and safely through increased flexibility in drug development and regulation. David A. Brindley University of Oxford, and CASMI, Oxford, UK; and Harvard Stem Cell Institute, Massachusetts, USA.

david.brindley@ndorms.ox.ac.uk Richard W. Barker CASMI, Oxford, UK.

Peter J. Lachmann University of Cambridge, UK.

\section{Big data for a sustainable future}

As discussions on Sustainable Development Goals end this week at the United Nations General Assembly in New York, I call for more 'big data' to help secure a sustainable future (see also D. Griggs et al. Nature 495, 305-307; 2013). We should be collecting big data that can be used to model and test an array of different scenarios for sustainably transforming the production and consumption of energy, improving food and water security, and eradicating poverty.

Managing these issues will also help to rebalance important biogeochemical cycles (especially the carbon, nitrogen and phosphorus cycles), mitigate climate change, reverse ocean acidification and reduce the loss of biodiversity. Big data will help to illuminate the origins, nature and scale of these challenges, and how they relate to one another.

National databases and research centres can be linked to create huge databases. Initiatives similar to those of the Intergovernmental Panel on Climate Change and the Global Ocean Observing System could fill the gaps in scientific, technical and socio-economic data. New initiatives such as Global Pulse (www.unglobalpulse.org) could help in mining and mobilizing big data, which are available in real time as a result of the explosive growth in new media.

The collection and use of big data sets needs to be coordinated globally, between regions and countries, as well as between relevant agencies and institutions. The United Nations and the International Council for Science could help to forge these collaborative initiatives and networks.

Hubert Gijzen UNESCO Regional Science Bureau for Asia and the Pacific, Jakarta, Indonesia.

h.gijzen@unesco.org

\section{Great scientists and society}

Robert White and colleagues point out that most scientific luminaries from centuries past were religious (Nature 501, 33; 2013). This says a great deal about the societies that these scientists lived and worked in, but little about the value or truth of a theistic world view, as can be seen by considering what else these great names have in common: they were all men. Simon Vaughan University of Leicester, UK. simon.vaughan@le.ac.uk 